\title{
Percent Predicted Forced Inspiratory Flow Maximum
}

National Cancer Institute

\section{Source}

National Cancer Institute. Percent Predicted Forced Inspiratory Flow Maximum. NCI

Thesaurus. Code C112379.

Forced inspiratory flow for a portion of the FVC curve at the point where the maximum portion of FVC is already inhaled as a proportion of the predicted normal value. (CDISC) 